\title{
Dedekind's Abstract Concepts: Models and Mappings ${ }^{\dagger}$
}

Wilfried Sieg* and Dirk Schlimm**

\author{
*Department of Philosophy, Carnegie Mellon University, Pittsburgh, Penn. 15213, U.S.A. \\ E-mail: ws15@andrew.cmu.edu \\ ** Department of Philosophy, McGill University, Montreal, Québec H3A 2T7, Canada. \\ E-mail: dirk.schlimm@mcgill.ca
}

\begin{abstract}
Dedekind's mathematical work is integral to the transformation of mathematics in the nineteenth century and crucial for the emergence of structuralist mathematics in the twentieth century. We investigate the essential components of what Emmy Noether called, his 'axiomatic standpoint': abstract concepts (for systems of mathematical objects), models (systems satisfying such concepts), and mappings (connecting models in a structure-preserving way).
\end{abstract}

\section{INTRODUCTION: MATHEMATICAL CONTEXTS}

The present paper continues the analysis of Dedekind's methodology we presented in our earlier essay [Sieg and Schlimm, 2005]. In a parenthetical but topical remark we observed: 'The introduction of the general concept of mapping and its structurepreserving variety for mathematical investigations is perhaps the methodologically most distinctive and most radical step in Dedekind's work' [2005, p. 121]. In this sequel we systematically expand on our observation. ${ }^{1}$ Such an expansion requires, first of all, a deepened understanding of Dedekind's axiomatic standpoint that is closely related to Hilbert's existential or structural axiomatics. ${ }^{2}$ Thus, Section 1 argues that both

\footnotetext{
$\dagger$ The translations of German texts are mostly our own, unless they are quoted from an English edition. We thank Dr Helmut Rohlfing from the Niedersächsische Staats- und Universitäts-Bibliothek in Göttingen for access to the unpublished Dedekind manuscripts.

${ }^{1}$ Most of the historical considerations on mappings presented here had been part of the penultimate draft of our [2005], but were then isolated out into a separate essay. The work on this 'complementary' essay was restarted only in late 2012 and has profited from Sieg's continuing work with Becky Morris on Dedekind's structuralism [Sieg and Morris, 2014] reflected in Section 1 and our Conclusion. We would also like to thank Erich Reck, Ansten Klev, and an anonymous referee for comments on an earlier draft of this paper.

${ }^{2}$ Existential or structural axiomatics has to be distinguished from formal axiomatics. The former was brought to life for geometry in [Hilbert, 1899] and for the arithmetic of real numbers in [Hilbert,
} 
Dedekind and Hilbert axiomatically define abstract concepts for systems or sets of objects; the characteristic conditions of these concepts (axioms) are taken as starting points for proofs. Once such concepts have been introduced and various systems that fall under them have been considered, it is extremely natural to explore correspondences or, in Dedekind's words, 'real connections' between those systems — via mappings. Such investigations, based on Dedekind's most distinctive methodological step, are consequently grounded in his axiomatic standpoint. How Dedekind's notion of structure-preserving mappings evolved is analyzed in Section 2.

Dedekind's mathematical work is integral to the transformation of mathematics in the nineteenth century and crucial for the emergence of structuralist mathematics in the twentieth century. Bourbaki's structuralism, in particular, stands in the tradition of Dedekind. Indeed, Bourbaki traces his approach to Dedekind through Emmy Noether and Hilbert; see [Dieudonné, 1970] and [Bourbaki, 1994, pp. 17-31]. One can say more generally that for any structuralist approach to mathematics or any view of mathematics as a science of patterns, preserving structural features of systems via suitable mappings is critical. These features reflect the fact that the systems satisfy the characteristic conditions of an abstract concept; their preservation makes it meaningful to talk, as Dedekind does with great emphasis, of Abbildung (mapping) and Bild (image).

The notion of Abbildung points, however, also to the past. Gauss and others had used the very term Abbildung already in the $1820 \mathrm{~s}$ - see [Gauss, 1825a] and his letter to Hansen [1825b] — for mappings from one surface to another, thus, in a geometric context. ${ }^{3}$ The ordinary meaning of the term is highlighted, both in Hansen's letter and Gauss's paper, by the comparison with perspectival representations and applications in cartography. Dedekind, always extremely careful when choosing his terminology, was clearly aware of this connection to Gauss and to the ordinary meaning: in his letter to Keferstein, he corrects Keferstein's understanding of Abbildung and Bild in [Keferstein, 1890] by writing:

Here is a confusion between mapping and image; instead of 'mapping $\bar{\varphi}\left(S^{\prime}\right)$ ' it should be 'mapping $\bar{\varphi}$ of the system $S^{\prime}$ '. Not $\bar{\varphi}\left(S^{\prime}\right)$ but $\bar{\varphi}$ is a mapping (the picturing painter) that generates from the system (the original) $S^{\prime}$

1900]. It is centered around a 'structural definition'; that definition is formulated with a restricted vocabulary, and its characteristic conditions are taken as starting-points for rigorous but non-formal proofs. The latter, in contrast, is the standard modern approach involving a formal language, a logical calculus, and an appropriate semantics. Through Hilbert's and Bernays's work in the 1920s, formal axiomatics has become so prominent that it is for many identified with axiomatics proper. See the Introduction to [Sieg, 2013] and [Sieg, 2014] for a detailed discussion of these two ways of Hilbert's axiomatics. The existential axiomatic approach was sustained throughout Hilbert's thinking about the foundations and practice of mathematics. As to semantics, $c f$. fn. 17 below.

${ }^{3}$ In his letter of 11 December 1825 to Hansen, who had inquired about his 1825 paper, Gauss emphasized that he had investigated the general concept 'einer Darstellung einer Fläche auf der andern, die in der That gar nichts weiter enthält, als dass jedem Punkt der einen nach irgend einem stetigen Gesetz ein Punkt der andern korrepondieren soll. Es mag erst etwas Abstraction kosten, sich zu diesem allgemeinen Begriff zu erheben: dann fühlt man sich aber auch wirklich auf einem höhern Standpunkt, wo alles in vergrösserter Klarheit erscheint.' 
the image $\bar{\varphi}\left(S^{\prime}\right)=S$. Such confusions can become quite dangerous in our investigation. $^{4}$

In Dedekind's work the notion of Abbildung emerged during the 1870s. At the end of the decade, he makes a remarkably general statement concerning the philosophical significance of Abbildungen in [Dirichlet, 1879], articulates it comprehensively in the preface to WZ, ${ }^{5}$ and refers back to both places in a note to Supplement XI of [Dirichlet, 1894]. The note reveals the importance of that notion for Dedekind:

It is stated already in the third edition of the present work (1879, footnote on p. 470) that the entire science of numbers is also based on this intellectual ability to compare a thing $a$ with a thing $a^{\prime}$, or to relate $a$ to $a^{\prime}$, or to let $a$ correspond to $a^{\prime}$, without which no thinking at all is possible. The development of this thought has meanwhile been published in my essay 'Was sind und was sollen die Zahlen?'6

Dedekind's perspective on mappings should be kept in mind, as we approach in the first section the systematic relevance of structure-preserving mappings.

\section{MODELS AND AXIOMS}

In her brief comment on SZ, Emmy Noether remarks that Dedekind's axiomatic standpoint can be clearly seen already in this 1872 essay and in the explanatory remarks he made in his letters of 10 June and 27 July 1876 to Lipschitz. ${ }^{7}$ Dedekind articulated his methodological standpoint most succinctly in WZ and the famous 1890 letter to Keferstein, but neither in the essay nor in the letter does Dedekind speak of 'axioms'. Indeed, there are only two occurrences of the word 'Axiom' in Dedekind's writings assembled in the three volumes of his Gesammelte mathematische Werke; both are found in SZ. One occurrence follows the formulation of the 'essence of continuity' for the

\footnotetext{
${ }^{4}$ Here is the German text from [Sinaceur, 1974, p. 276]: 'Hier findet sich eine Verwechselung zwischen Abbildung und Bild; statt 'Abbildung $\bar{\varphi}\left(S^{\prime}\right)$ ', müßte es heißen 'Abbildung $\bar{\varphi}$ des Systems $S^{\prime}$. Nicht $\bar{\varphi}\left(S^{\prime}\right)$, sondern $\bar{\varphi}$ ist eine Abbildung (der abbildende Maler), die aus dem System (Original) $S^{\prime}$ das Bild $\bar{\varphi}\left(S^{\prime}\right)$ erzeugt. Solche Verwechselungen können aber bei unserer Untersuchung recht gefährlich werden.'

${ }^{5}$ Here and in the following we refer to Dedekind's Was sind und was sollen die Zahlen? as WZ and to his Stetigkeit und irrationale Zahlen as SZ.

${ }^{6}$ [Dirichlet, 1894, p. 456]. The German text is: 'Schon in der dritten Auflage dieses Werkes (1879, Anmerkung auf S. 470) ist ausgesprochen, dass auf dieser Fähigkeit des Geistes, ein Ding a mit einem Ding $a^{\prime}$ zu vergleichen, oder $a$ auf $a^{\prime}$ zu beziehen, oder dem $a$ ein $a^{\prime}$ entsprechen zu lassen, ohne welche überhaupt kein Denken möglich ist, auch die gesamte Wissenschaft der Zahlen beruht. Die Durchführung dieses Gedankens ist seitdem veröffentlicht in meiner Schrift Was sind und was sollen die Zahlen?'

${ }^{7}$ Noether's comment is found in [Dedekind, 1932, p. 334]. Here is the German text: 'Die an diese klassische Schrift anknüpfende Entwicklung ist so bekannt, dass wir glauben auf Erläuterungen verzichten zu dürfen. Im übrigen verweisen wir - als Dedekinds eigene Erläuterungen darstellend — auf die Briefe an Lipschitz vom 10. Juni und 27. Juli 1876 ([Chap.] LXV), insbesondere auf die darin enthaltene axiomatische Auffassung.'
} 
geometric line, namely, that every cut (of the geometric line) is determined by a point. Dedekind writes, 'The assumption of this property of the line is nothing but an axiom by which we attribute to the line its continuity, by which we think continuity into the line.' 8 The other occurrence is found in the preface to SZ where Dedekind mentions [Cantor, 1872], refers to what Cantor himself calls an 'axiom', and asserts: 'As I find on a quick reading, the axiom given in Section 2 of that paper [of Cantor's], aside from the outer form of presentation, agrees with what I designated in Section 3 as the essence of continuity.'

\subsection{Structural Definitions}

Why do we then attribute an axiomatic standpoint to Dedekind, if the crucial constituents, axioms, seem to be missing in his investigations? ${ }^{9}$ And, if there are no axioms, of what can we have models in the modern logical sense of the word? To answer these questions let us first note that both Dedekind and Frege use the term 'axiom' to denote true statements about definite mathematical objects: the axiom of continuity is true of the geometric line. However, one should notice Dedekind's strong emphasis on the fact that we attribute continuity to the line, that we think continuity into the line. This goes hand in hand with the observation, at the end of section III of SZ, that he is 'utterly unable to adduce any proof of its correctness'. Indeed, he insists there that, 'if space has at all a real existence it is not necessary for it to be continuous; many of its properties would remain the same even if it were discontinuous. ${ }^{10}$

In WZ Dedekind presents a model for Euclidean geometry that is everywhere discontinuous and claims:

... despite the fact that this space lacks continuity and contains gaps, as far as I can see, all constructions that occur in Euclid's Elements can be carried out in exactly the same way as in a completely continuous space; thus, the lack of continuity of this space would not be noticed at all, would not be sensed at all, in Euclid's science. ${ }^{11}$

While Frege's perspective on axioms is a traditional one, we suggest that Dedekind's practice reveals an understanding of axioms (without using the word) that is much closer to the sense in which Hilbert, Bourbaki, and most modern mathematicians use

${ }^{8}$ [Dedekind, 1872, p. 11]. Here is the German text: 'Die Annahme dieser Eigenschaft der Linie ist nichts als ein Axiom, durch welches wir erst der Linie ihre Stetigkeit zuerkennen, durch welches wir die Stetigkeit in die Linie hineindenken.'

${ }^{9}$ Our answer to this question is diametrically opposed to that given in [Klev, 2011].

${ }^{10}$ In his letter to Lipschitz, [Dedekind, 1932, p. 479], one finds this corresponding remark: '... Raumbegriff [ist] gänzlich unabhängig ... von der Vorstellung der Stetigkeit ... Mit diesen Bemerkungen, die nur weitere Ausführungen von den in meiner Schrift ausgesprochenen Gedanken sind ...'

${ }^{11}$ [Dedekind, 1888, p. VII]. The German text is: ‘... aber trotz der Unstetigkeit, Lückenhaftigkeit dieses Raumes sind in ihm, so viel ich sehe, alle Konstruktionen, welche in Euklids Elementen auftreten, genau ebenso ausführbar wie in dem vollkommen stetigen Raume; die Unstetigkeit dieses Raumes würde daher in Euklids Wissenschaft gar nicht bemerkt, gar nicht empfunden werden.' 
the word. That sense, and its striking difference from Frege's understanding, comes out in Hilbert's correspondence with Frege from 1899-1900; the exchange of letters concerns almost exclusively Hilbert's Grundlagen der Geometrie.

Hilbert had given a novel axiomatization of geometry in his Festschrift; the axioms appear under the heading 'Erklärung' in this way:

We think three different systems of things: we call the things of the first system points and denote them by $A, B, C, \ldots$; we call the things of the second lines and denote them by $a, b, c, \ldots$; we call the things of the third system planes and denote them by $\alpha, \beta, \gamma, \ldots ; \ldots$ We think the points, lines, planes in certain mutual relations ...; the precise and complete description of these relations is obtained by the axioms of geometry. [Hilbert, 1899, p. 437]

The axioms are systematically organized in five groups that pertain to particular concepts; the axioms of group II, for example, concern 'between' and are introduced by the remark:

The axioms of this group define the concept 'between' and make it possible on account of this concept to order the points on a line, in a plane, or in space. ${ }^{12}$

Frege criticized this use of 'axioms' and questioned, in particular, how they could be viewed as definitions. Hilbert responded by pointing out that the Erklärung of the concept 'between' provides a proper definition, because its characteristic conditions (Merkmale) are given by the five axioms of group II that involve 'between'. He writes, if one wanted to take 'definition' in exactly the traditional sense, then one would have to say:

'Between' is a relation for the points of a line that satisfies the following characteristic conditions: II 1 ... II $5 .^{13}$

He emphasizes that he would have absolutely no objection, if his axioms were simply called Merkmale (of what Frege would later consider as a second-level concept). Having briefly discussed the stark opposition of their views on consistency and truth, Hilbert comes back to the main issue (Hauptsache) and asserts most clearly:

The renaming of 'axioms' as 'characteristic conditions' etc. is a pure formality and, in addition, a matter of taste — in any event, it is easily accomplished. ${ }^{14}$

12 [Hilbert, 1899, p. 439]. Here is the German text: 'Die Axiome dieser Gruppe definieren den Begriff "zwischen” und ermöglichen auf Grund dieses Begriffes die Anordnung der Punkte auf einer Geraden, in einer Ebene und im Raume.'

${ }^{13}$ [Frege, 1980, p. 11]. Here is the German text: ' "Zwischen” ist eine Beziehung für die Punkte einer Geraden, die folgende Merkmale hat: II 1 ... II 5.'

${ }^{14}$ [Frege, 1980, p. 12]. Here is the German text: 'Die Umnennung "Merkmale" statt "Axiome" etc. ist doch nur eine Äusserlichkeit und überdies Geschmackssache - ist aber jedenfalls leicht zu bewerkstelligen.' 
Modern mathematicians speak, in just this sense, of the axioms for groups or fields as specifying the definition of an abstract notion or as giving a structural definition. With such a definition Dedekind had introduced the notion of field, Zahlkörper or simply Körper, in Section 159 of his Supplement X to [Dirichlet, 1871]. It was to provide, 'from a higher standpoint', the foundation for higher algebra and the closely connected parts of number theory:

We shall denote by field every system of infinitely many real or complex numbers, which is closed and complete in such a way that addition, subtraction, multiplication, and division of any two of these numbers always yields again a number of the same system. ${ }^{15}$

In (SZ, p. 6) Dedekind refers back to this section when using the notion of field and applying it to the system $R$ of rational numbers; that system, he asserts, satisfies the characteristic condition of a field. ${ }^{16}$ Showing that a system of numbers falls under such a notion (or is an instance of it) can be viewed, from a modern logical perspective, as giving an interpretation or exhibiting a model of the 'axioms' ${ }^{17}$ Instead of elaborating this modern perspective, we describe how this is reflected in Dedekind's practice by presenting and analyzing his discussion in Sections I and II of SZ.

Dedekind's objective in SZ is to obtain a continuous ordered system, and it is for this purpose that he investigates different instances of an ordered system. Call a system $O$ an ordered system if and only if there is a relation $R$ on $O$, such that $(1) R$ is transitive, (2) between any two different elements $u$ and $v$ in $O$ there are infinitely many elements

15 [Dirichlet, 1871, p. 424]. The German text is: 'Unter einem Körper wollen wir jedes System von unendlich vielen reellen oder complexen Zahlen bezeichnen, welches in sich so abgeschlossen und vollständig ist, dass die Addition, Subtraction, Multiplication und Division von je zwei dieser Zahlen immer wieder eine Zahl desselben Systems hervorbringt.' See also the discussion of Dedekind's axiomatic introduction of the notion of Dualgruppe in [Schlimm, 2011, pp. 53-57].

${ }^{16}$ The German text in SZ is this: 'Dieses System, welches ich mit $R$ bezeichnen will, besitzt vor allen Dingen eine Vollständigkeit und Abgeschlossenheit, welche ich an einem anderen Orte [here follows the reference to the second edition of Dirichlet's lectures on number theory from 1871] als Merkmal eines Zahlkörpers bezeichnet habe, und welche darin besteht, dass die vier Grundoperationen mit je zwei Individuen in $R$ stets ausführbar sind, ...'

${ }^{17}$ In the early development of modern mathematical logic, the semantic concepts of satisfiability and validity were defined in just this way: this holds for Hilbert's lectures from 1917-18 [Hilbert, 1917/18], for his 1928 book with Ackermann [Hilbert and Ackermann, 1928], and for Gödel's thesis [Gödel, 1929]; see [Gödel, 1986, pp. 66-68]. Gödel's discussion is particularly perspicuous and closely follows the presentation in Hilbert and Ackermann's book. Logical expressions are built up from individual, function, and propositional variables; consider now a logical expression containing function variables $F_{1}, \ldots, F_{k}$, free individual variables $x_{1}, \ldots, x_{l}$, and propositional variables $X_{1}, \ldots, X_{m}$. Gödel defines: 'Wir sagen von einem System (sämtlich in demselben Denkbereich definierter) Funktionen $f_{1}, f_{2}, \ldots, f_{k}$ und (ebenfalls demselben Denkbereich angehörenden) Individuen, $a_{1}, a_{2}, \ldots, a_{l}$, sowie Aussagen $A_{1}, A_{2}, \ldots, A_{m}-$ von diesem System $S=$ $\left(f_{1}, f_{2}, \ldots, f_{k} ; a_{1}, a_{2}, \ldots, a_{l} ; A_{1}, A_{2}, \ldots, A_{m}\right)$ sagen wir, dass es den logischen Ausdruck erfülle, wenn es in denselben eingesetzt einen (in dem betreffenden Denkbereich) wahren Satz ergibt.' Gödel emphasizes then that the 'Bedeutung' of logical expressions given in this way can be directly expanded to the case when the language contains individual and function constants. 
$z$, in the sense that either $R(u, z)$ and $R(z, v)$, or $R(v, z)$ and $R(z, u)$, and (3) for every element $x$ in $O$ there is a partition of $O$ into two infinite subsets $O_{1}$ and $O_{2}$, such that (i) $x$ is in $O_{1}$, (ii) $R(z, x)$ holds precisely for all elements $z$ of $O_{1}$ different from $x$, and (iii) $R(z, y)$ holds for all elements $z$ in $O_{1}$ and $y$ in $O_{2}$. For any given element $x$ in $O$, the partition of (3) satisfying (i)-(iii) is necessarily unique; it is called by Dedekind the cut determined by $x .^{18}$

Our reformulation of Dedekind's way of proceeding is based on his later introduction of the notion of a simply infinite system in WZ. Here in SZ, he formulates the above principles for particular domains and particular relations on those domains: he does so in Section I for the rational numbers with their ordinary ' $x$ is less than $y$ ' relation and in Section II for the geometric line with the relation ' $p$ is to the left of $q$ '. Section II has the heading 'Comparison of the rational numbers with the points of a straight line' (Vergleichung der rationalen Zahlen mit den Punkten einer geraden Linie). In its very first sentence Dedekind remarks that the properties (1)-(3) of the less-than relation between rational numbers 'recall the corresponding relations of position of the points of a straight line $L$ ', and he formulates then the properties (1)-(3) for the 'to the left of relation' between the points of $L$. At the end of Section II, Dedekind emphasizes that the laws for the one domain correspond completely to those of the other. This correspondence of laws for the rational numbers and the geometric line is at first described as an analogy (Analogie). ${ }^{19}$ The analogy can be turned, 'as is well known', into a real connection (wirklicher Zusammenhang) — between the elements of the separate domains.

\subsection{Real Connections}

The real connection between $R$ and $L$ is established by choosing on the straight line a definite starting point (Anfangspunkt) or zero point (Nullpunkt), as well as a definite unit of length. Having made these choices, to each rational number corresponds exactly one point of the line. Dedekind remarks that this correspondence is, in modern terminology, structure-preserving: if the rational numbers $x$ and $y$ stand in the relation ' $x$ is less than $y$ ', then the corresponding points $p$ and $q$ stand in the relation ' $p$ is to the left of $q$ '. A similar structure-preserving correspondence between number fields was introduced by Dedekind in [Dirichlet, 1871, pp. 424-425] under the name substitution (Substitution), but here there is no correspondence between systems of different kinds of mathematical objects, and the operations that are being preserved are those of the original field. ${ }^{20}$ Thus it is quite clear that in SZ a crucial connection, a real correspondence, between different systems is adumbrated, but not yet fully conceptualized.

The tentative character of Dedekind's methodological stance in SZ shows itself also at a different and pivotal place. Dedekind remarks at the beginning of Section III (and proves in Section IV) that the correspondence between $R$ and $L$ is such that infinitely

\footnotetext{
${ }^{18}$ This is not exactly Dedekind's formulation, but a gently simplified and equivalent one.

${ }^{19}$ This use of 'analogy' was not uncommon at the time; see, e.g., [Beltrami, 1868]. For a more general discussion of characterizations of analogies, see [Schlimm, 2008].

${ }^{20}$ The full definition from [1871] is discussed in Section 3.1 below.
} 
many geometric points do not correspond to any rational number. The central concept of continuity is formulated at first for the geometric line in Section III: not only does every point determine a cut (as expressed above by (3)), but every cut is determined by an element of $L$. This is the 'axiom' we briefly discussed already. In Section V, Dedekind proves the main theorem of SZ, namely, that the system of all 'real numbers' is continuous. That can be done of course only after an appropriate order relationship has been introduced via cuts that 'completely define' the new real numbers. (The details of the ordering and its introduction are presented in our paper [2005, p. 139].) Note that the cuts themselves are not viewed by Dedekind as an instantiation of the abstract notion of an ordered system. Rather, he asserts in a crucial passage that an individual irrational number is being 'created' corresponding to any cut that is not determined (engendered or produced) by a rational number. He writes:

Whenever, then, we have to do with a cut $\left(A_{1}, A_{2}\right)$ produced by no rational number, we create a new, an irrational number $\alpha$, which we regard as completely defined by this cut $\left(A_{1}, A_{2}\right)$; we shall say that the number $\alpha$ corresponds to this cut, or that it produces this cut. From now on, therefore, to every definite cut there corresponds a definite rational or irrational number, and we regard two numbers as different or unequal always and only when they correspond to essentially different cuts. ${ }^{21}$

Four years later, this perspective is elaborated in letters to Lipschitz in which Dedekind emphasizes that the irrational numbers are a 'unique creation' and are 'created in a single step'.22 The latter becomes an explicit requirement in [Dedekind, 1877] where he writes that 'one should demand that all irrational numbers be engendered simultaneously by a common definition'.

In sharp contrast to this view of irrational numbers and at the very beginning of the period of reflections on method in 1872, the rational numbers are individually obtained through a genetic construction starting with the natural numbers; see SZ, pp. 5-6. ${ }^{23}$

${ }^{21}$ [Dedekind, 1932, p. 325]. The German text is: 'Jedesmal nun, wenn ein Schnitt $\left(A_{1}, A_{2}\right)$ vorliegt, welcher durch keine rationale Zahl hervorgebracht wird, so erschaffen wir eine neue, eine irrationale Zahl $\alpha$, welche wir als durch diesen Schnitt $\left(A_{1}, A_{2}\right)$ vollständig definiert ansehen; wir werden sagen, dass die Zahl $\alpha$ diesem Schnitt entspricht, oder dass sie diesen Schnitt hervorbringt. Es entspricht also von jetzt ab jedem bestimmten Schnitt eine und nur eine bestimmte rationale oder irrationale Zahl und wir sehen zwei Zahlen stets und nur dann als verschieden oder ungleich an, wenn sie wesentlich verschiedenen Schnitten entsprechen.'

${ }^{22}$ In his letter of 10 June 1876 Dedekind speaks of a single creation of new, irrational numbers (eine einzige Schöpfung von neuen, irrationalen Zahlen) and in the letter of 21 July 1876 he writes that the irrational numbers are defined in one step (dass die irrationalen Zahlen mit einem Schlage definirt werden). The remarks are found in [Dedekind, 1932] on p. 470 and p. 476, respectively.

${ }^{23}$ Hilbert contrasts in his [1900] the axiomatic to the genetic method when introducing the 'most general concept of real number'. His description of the latter method agrees fully with Dedekind's understanding at this early point; see fn 24 . Even the starting-point for the successive extensions is discussed in almost identical terms: 'Ausgehend von dem Begriff der Zahl 1, denkt man sich gewöhnlich durch den Prozess des Zählens zunächst die weiteren ganzen rationalen positiven Zahlen 2, 3, 4 ... entstanden und ihre Rechnungsgesetze entwickelt; ...' 
And Dedekind claims that 'the negative and fractional numbers have [thus] been created by the human mind.' This genetic view of the creation of individual numbers was even more explicit and pronounced in Dedekind's [1854]. ${ }^{24}$ In manuscripts from around 1872, however, we find a move away from this form of creating numbers one at a time; it is replaced by novel and consciously 'axiomatic' extensions of the number concept: The conceptual extensions avoid the subtle circularity of the earlier constructions and provide also a way of satisfying the requirements that the numbers 'be engendered simultaneously by a common definition'.

The extensions of the number concept take for granted the natural numbers as the fundamental starting point; but this basis had not yet been secured in 1872 as is clear from the description in SZ where Dedekind writes:

I regard the whole of arithmetic as a necessary, or at least natural, consequence of the simplest arithmetic act, that of counting, and counting itself as nothing else than the successive creation of the infinite series of positive integers in which each individual is defined by the immediately preceding; the simplest act is the passing from an already formed individual to the consecutive new one to be formed. 25

In the manuscript [Dedekind, 1872/78] one can trace Dedekind's development from this stepwise definitional creation of individual natural numbers to the first formulation of the so-called Dedekind-Peano axioms. Zahlen is the title of the last section of this manuscript that is to give a 'direct treatment of the system $Z$ of the natural (i.e., the whole positive rational) numbers'. The direct treatment is then presented under the heading 'Charakteristik des Systems Z':

There exists an injective mapping from $Z-$ if $T$ is a part of $Z$, then the image of $T$ shall be denoted by $T^{\prime}$ - , that has the following properties.

I. $Z^{\prime}$ is a part of $Z$.

II. There exists a number (i.e., a thing contained in $Z$ ) that is not contained in $Z^{\prime}$. This number shall be called 'One' and denoted by 1 .

${ }^{24}$ That is described in detail in our paper [2005], where we also point out the 'subtle circularity' in Dedekind's construction. However, in Section 3.3, pp. 134-135 of that paper, we discuss the very first steps towards an axiomatic analysis of the number systems. The more systematic model constructions mentioned next are presented in Section 4 of that paper under the heading 'Creating models'.

25 [Dedekind, 1932, p. 317]. The German text is: 'Ich sehe die ganze Arithmetik als eine notwendige oder wenigstens natürliche Folge des einfachsten arithmetischen Aktes, des Zählens, an, und das Zählen selbst ist nichts anderes als die sukzessive Schöpfung der unendlichen Reihe der positive ganzen Zahlen, in welcher jedes Individuum durch das unmittelbar vorhergehende definiert wird; der einfachste Akt ist der Übergang von einem schon erschaffenen Individuum zu dem darauffolgenden neu zu erschaffenden.' 
III. A number chain (i.e, every part $T$ of $Z$, whose image $T^{\prime}$ is a part of $T$ ), which contains the number 1 is identical to $Z .^{26}$

This characteristic obviously builds on the notions of a system of things and of a similar mapping on such a system that emerged in the 1872/78 manuscript.

The discussion of $Z$ concludes this manuscript. Clearly, there is still an enormous gap that separates it from the full development of WZ; see Section 5 of our [2005]. Here let us note that the early draft lacks especially the definition of a simply infinite system as an abstract notion and the proof of the recursion theorem that provides the justification for defining mappings by recursion. All of this is contained in the third and penultimate draft of WZ that was written, according to Dedekind's note on the first page, in June and July of 1887 . The Zahlenreihe $N$ is introduced in Section 5, which comes in two variants in the manuscript. The first version has the title 'Die Reihe der natürlichen Zahlen', whereas the second one is entitled 'Die einfach unendlichen Systeme (Reihe der natürlichen Zahlen)'. The informal discussion that begins the first version of Section 5 does not contain the notion of a simply infinite system; it is replaced in the second version by ' 50 . Erklärung': a system $N$ is now called simply infinite just in case there is a similar mapping $\varphi$ of $N$ to itself such that $N$ appears as the chain of an element that is not contained in $\varphi(N)$. Dedekind remarks:

Every such mapping $\varphi$ from $N$ can be called an ordering of $N$. The elements of $N$ (with respect to this ordering) can be called natural numbers. ${ }^{27}$

And yet, Dedekind retains for the second variant an 'abstract' system of natural numbers. Having described the 'freeing of the elements [of $N$ ] from any other content (abstraction)' in exactly the same way as it is done in (WZ, \#73) he continues (in the manuscript picture the framed middle part of the page):

By this abstraction, the originally given elements $n$ of $N$ are turned into new elements $n$, namely into numbers (and $N$ itself is consequently also turned into a new abstract system $N$ ). Thus, one is justified in saying that the numbers owe their existence to an act of free creation of the mind. For our mode of expression, however, it is more convenient to speak of the numbers as of the original

${ }^{26}$ [Dugac, 1976, pp. 308-309]. The German text is: 'Es giebt eine deutliche Abbildung von $Z$ — ist $T$ ein Theil von $Z$, so soll das Bild von $T$ mit $T^{\prime}$ bezeichnet werden —, welche folgende Eigenschaften besitzt.

I. $Z^{\prime}$ ist Theil von $Z$.

II. Es giebt eine Zahl (d.h. ein in $Z$ enthaltenes Ding), welche nicht in $Z^{\prime}$ enthalten ist. Diese Zahl soll 'Eins' heissen und mit 1 bezeichnet werden.

III. Eine Zahlkette (d.h. jeder Theil $T$ von $Z$, dessen Bild $T^{\prime}$ ein Teil von $T$ ist), welche die Zahl 1 enthält, ist identisch mit $Z$.'

27 [Dedekind, 1887, p. 5]. The German text is: 'Jede solche Abbildung $\varphi$ von $N$ kann eine Anordnung von $N$ genannt werden. Die Elemente von $N$ (mit Rücksicht auf diese Anordnung) können natürliche Zahlen heissen.' 


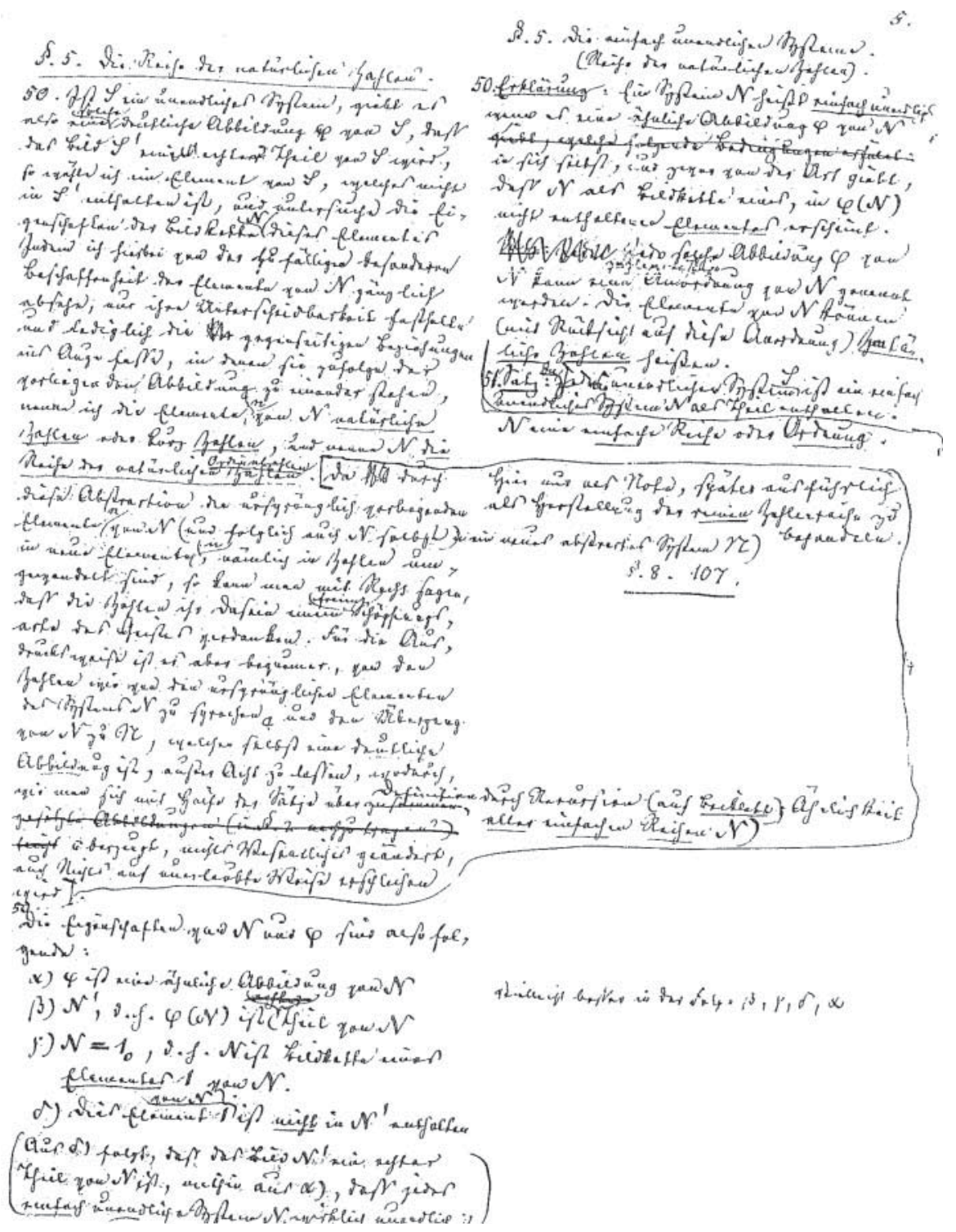

Fig. 1. From [Dedekind, 1887]: The two versions of the beginning of Section 5. - The first version is on the left-hand side and comes under the heading 'Die Reihe der natürlichen Zahlen', whereas the second is written on the right-hand side of the page and is entitled 'Die einfach unendlichen Systeme. (Die Reihe der natürlichen Zahlen).'

elements of the system $N$ and to disregard the transition from $N$ to $N$, which itself is an injective mapping. Thereby, as one can convince oneself using the theorems regarding definition by recursion ... nothing essential is changed, nor is anything obtained surreptitiously in illegitimate ways. ${ }^{28}$

28 [Dedekind, 1887, p. 5]. The German text is found in our paper [2005, p. 165, fn 62]. 
These remarks are not included in WZ. Rather, Dedekind points in \#73 - the natural place where they could have been situated — to Remark 134. There he gives a rough argument that can be viewed as a model-theoretic proof and establishes that 'categoricity' implies 'elementary equivalence'. That proof gives mathematical-logical substance to the elusive remark above that 'Thereby ... nothing essential is changed, nor is anything obtained surreptitiously in illegitimate ways' and, in a deeply related way, is taken by Dedekind to justify completely the notion of numbers given in Erklärung 73. Thus, the methodological significance of structure-preserving mappings cannot be over-emphasized: they allow us, as already adumbrated in SZ, to establish real connections between objects of different systems and recognize corresponding laws. Before discussing their methodological significance in some detail in our concluding remarks, we explore next their mathematical origins.

\section{MAPPINGS}

Dedekind's mathematics in his supplement to [Dirichlet, 1879] is modern, startlingly different from how he started his foundational work in his Habilitationsrede of 1854, Über die Einführung neuer Funktionen in der Mathematik, and it is even substantively different from his work in SZ. The crucial new aspect is the use of Abbildungen. The title of the Habilitationsrede promises the introduction of new functions and Dedekind refers to the talk prominently in the Introduction to WZ, but the central issue in [1854] was that of extending functions and operations ${ }^{29}$ from narrow to broader generated domains of numbers. The extensions were to be achieved in accord with the principle of the permanence of laws: the new functions must be defined in such a way that they satisfy the laws for those already in use (so that the new functions can be considered as generalizations of the earlier ones). What actually counts as a function and how functions can be presented, those widely discussed questions of the eighteenth and nineteenth century, Dedekind did not address in [1854]. ${ }^{30}$

${ }^{29}$ Operations are the seven elementary functions: addition, multiplication, and exponentiation together with their inverses subtraction, division, taking roots and logarithms. This seems to have been common terminology; see for example [Schröder, 1873].

${ }^{30}$ [Volkert, 1986, pp. 47-79] distinguishes between three different notions of function: the 'genetic' concept of function that is based on explicitly given rules (Euler); Lacroix's and Cauchy's understanding, according to which functions are characterized as a relation between an independent and a dependent variable; a notion of function that is based on a pointwise correlation between domain and range (Dirichlet). All of these, however, were considered almost exclusively as numbertheoretic, i.e., as relating numbers, be they natural, real, or complex. That fact is reflected in the very name and content of lectures and books on Funktionentheorie; that subject is not a general theory of functions, but rather complex analysis. [Monna, 1972] and [Youschkevitch, 1976] describe matters in very informative ways.

Of the important papers of the nineteenth century we mention Riemann's Habilitationsschrift from 1854; it starts with an extremely thoughtful and thorough historical discussion and describes in particular the representability of 'functions' by trigonometric series. That discussion covers of course Dirichlet's Über die Darstellung ganz willkürlicher Funktionen durch Sinus- und Cosinusreihen (1837) that contains Dirichlet's famous definition of a function; the paper is reprinted in [Dirichlet, 1889], and the relevant passage is found on pp. 133-134. 
Dedekind's mathematical and meta-theoretic investigations required not only a concept of 'arbitrary' function on particular number domains, but functions between completely different domains. As we saw, even to express that there is a correspondence between points on a straight line and rational numbers, functions are needed from objects belonging to one domain (the geometric points) to objects belonging to an entirely different domain (the rational numbers). Such generalized 'functional' relations between objects from possibly different systems have various names in Dedekind's writings: 'correspondences', 'substitutions', 'permutations', and ultimately 'mappings'. We discuss the subtle differences between them in the next sections. The basic informal concept to be captured is that of law-like correspondences as already formulated by Gauss in the 1820s; see our Introduction. The problem of clarifying 'law-likeness' is side-stepped in the later developments by Zermelo who introduced in his [1908] an extensional concept of Abbildungen as sets (of unordered pairs).

\subsection{Correspondences}

Already in the later 1850s, Dedekind was familiar with structure-preserving functions between domains other than numbers. In one of his earliest works on algebra, the notes Aus den Gruppen-Studien (1855-1858) [Dedekind, 1855-58], Dedekind implicitly makes use of functions between elements (and sets of elements) of different groups; the functions obey certain conditions (they are what we now call surjective homomorphisms), but these conditions are not formulated as properties of the functions themselves. Rather, Dedekind writes that the objects from different groups correspond to each other. Dedekind focuses on the relations between groups, subgroups, and quotient groups, but does not denote the functions between them with a symbol and has no particular name for them. Only when two groups are equivalent (isomorphic) does he speak of a substitution that changes one group into an equivalent one. In this case he writes $S=\left(\begin{array}{ccc}a & b & c \\ a^{\prime} & b^{\prime} & c^{\prime}\end{array}, \ldots\right)$, following Cauchy. ${ }^{31}$ Dedekind investigates compositions of substitutions and remarks that the set (Komplex) of all substitutions itself forms a group. He also mentions other domains to which the theory of groups can be applied, namely, rotations and quaternions. Emmy Noether points, in her comments on these notes, to the remarkable fact that Dedekind possessed already in the late $1850 \mathrm{~s}$ concepts and methods of abstract group theory [Dedekind, 1932, p. 445]. However, Dedekind remarks in a letter to Frobenius ${ }^{32}$ that he was interested in group theory only insofar as it was fruitful for his other investigations. Since there was no further need to study structure-preserving mappings, Dedekind did not explore a more general notion of function. Thus, at this point he does not mention mappings between different sorts of objects, does not investigate properties of functions in general, and does not have specific terminology for such properties.

\footnotetext{
${ }^{31}$ This is taken from [Scharlau, 1981, p. 61]; in the Gruppen-Studien Dedekind writes the upper row as ' $1, \theta, \theta^{\prime}, \ldots$ ' and the lower row as ' $1, \theta_{1}, \theta_{1}^{\prime}, \ldots$ '. Cauchy writes the new elements at the top, see $[1815$, p. 67$]$ and $[1844$, p. 172].

${ }^{32}$ Letter from 8 February 1895; [Dedekind, 1931, p. 419].
} 
In the lecture notes Eine Vorlesung über Algebra ${ }^{33}$ Dedekind defines a substitution as a process by which certain elements $a, b, c, \ldots$ are changed into or replaced by elements $a^{\prime}, b^{\prime}, c^{\prime}, \ldots$ However, he immediately restricts his attention to substitutions in which the set (Komplex) of elements $a, b, c, \ldots$ is identical to the set of elements $a^{\prime}, b^{\prime}, c^{\prime}, \ldots{ }^{34}$ Thus, 'substitution' is not used here in the sense of isomorphism as in Aus den Gruppen-Studien (1855-1858), but more generally as 'bijection'. The greater generality of substitutions is not discussed any further; instead, Dedekind investigates groups of substitutions and remarks that one could also apply the theory of groups to any finite number of 'things or concepts' which are closed under composition [Scharlau, 1981, p. 63].

During the 1860s Dedekind published only three short papers on probability theory and analysis, but he also worked on the first edition of Dirichlet's Vorlesungen über Zahlentheorie, which was published in 1863, and for the second edition of 1871 he added substantial and important supplements. In Supplement X (\$159), as we indicated earlier, he introduces the notion of a field as an infinite system of real or complex numbers that is closed under the basic arithmetical operations of addition, subtraction, multiplication, and division. He also defines a structure-preserving relation (homomorphism) between fields as follows: if to every number $a$ of the field $A$ there corresponds a number $b=\varphi(a)$, such that $\varphi\left(a_{1}+a_{2}\right)=\varphi\left(a_{1}\right)+\varphi\left(a_{2}\right)$ and $\varphi\left(a_{1} * a_{2}\right)=\varphi\left(a_{1}\right) * \varphi\left(a_{2}\right)$, then the numbers $b$ also form a field $B=\varphi(A)$. Dedekind imposes the restriction that not all elements of $A$ vanish (verschwinden), i.e., that at least one element is not mapped to zero, because otherwise division could not be applied to the elements of $B .^{35}$ This restriction indicates that Dedekind allows for the possibility that $\varphi$ is not injective. Implicitly assuming $\varphi$ to be injective and surjective (i.e., an isomorphism), but not mentioning any restrictions on $\varphi$, Dedekind calls $B$ the conjugate of $A$, and says that $B$ emerges (hervorgehen) from $A$ by the substitution $\varphi$. In this case, he states that there exists also a substitution $\psi$, such that $A=\psi(B)$. Dedekind remarks that if two fields are conjugate with a third one, then they are conjugate, too, and that every field is conjugate to itself; thus, the relation of being conjugate is an equivalence relation.

${ }^{33}$ The lecture notes were published in [Scharlau, 1981]. Their exact dating is problematic: Scharlau remarks that it seems likely that they are later elaborations of the lectures on higher algebra that Dedekind gave in Göttingen in the winter semesters of $1856 / 57$ and $1857 / 58$. According to the terminology used, Scharlau gives an upper bound: they were definitely written before Dedekind began working on Supplement X for the second edition of Dirichlet's Vorlesungen über Zahlentheorie, thus before 1870; see [Scharlau, 1981, p. 101].

${ }^{34}$ Here is the extended German text from [Scharlau, 1981, p. 60]: 'Unter Substitution versteht man im Allgemeinen jenen Process, durch welchen gewisse Elemente $a, b, c, \ldots$ in andere $a^{\prime}, b^{\prime}, c^{\prime}, \ldots$ übergehen oder durch diese ersetzt werden; wir betrachten im Folgenden nur die Substitutionen, bei welchen der Complex der ersetzenden Elemente $a^{\prime}, b^{\prime}, c^{\prime}, \ldots$ mit dem der ersetzten $a, b, c, \ldots$ identisch ist.'

${ }^{35}$ For a later explanation in Dedekind's own words: 'Hierbei sehen wir es als selbstverständlich an, dass die Zahl Null niemals den Nenner eines Quotienten bilden kann; wir setzen deshalb auch immer voraus, dass ein Körper mindestens eine von Null verschiedene Zahl enthält, weil sonst von einem Quotienten innerhalb dieses Systems gar nicht gesprochen werden könnte.' [Dirichlet, 1894, p. 453]. 
The comparison of Dedekind's presentation of fields with that of groups reveals striking similarities. He speaks of the correspondence between elements from different groups or fields, and of substitution in the case of an isomorphism between groups or fields. The statement that a new field is obtained from a given field by a substitution compatible with addition and multiplication is of the same form as the corresponding statement about groups. In both cases Dedekind observes that the relation given by substitutions is symmetric, reflexive, and transitive. One difference between the texts lies in the form in which substitutions are presented. In this respect the later presentation has a decidedly modern flavor. However, in regard to the level of generality it is restricted: we have seen that for Dedekind the elements of a group can be various kinds of objects, whereas the elements of fields are always numbers. ${ }^{36}$ Thus, substitutions between fields are number-theoretic functions.

In 1877 Dedekind published an account of his theory of ideals as Sur la Théorie des Nombres entiers algébriques. As in the supplements to Dirichlet's lectures, Dedekind defines a field to be a system of numbers. But, with regard to functions he now distinguishes terminologically between general functions and those that preserve structure: he describes a substitution quite generally as an act that changes objects or elements into new ones (as he did in Eine Vorlesung über Algebra). What he called substitutions in Aus den Gruppen-Studien (1855-1858) and in the second edition of Dirichlet's Vorlesungen [1871], namely isomorphisms, are now called permutations. ${ }^{37}$ Besides this terminological change Dedekind now also addresses directly properties of permutations:

A permutation changes two different numbers $\alpha, \beta$ in the field $\Omega$ into two different numbers $\alpha^{\prime}, \beta^{\prime}$ in the field $\Omega^{\prime}$, so that each number $\alpha^{\prime}$ in the field $\Omega^{\prime}$ corresponds to a single number $\alpha$ in the field $\Omega$. The correspondence can therefore be reversed in a unique manner. ${ }^{38}$

\subsection{Abbildungen}

In connection with his work on WZ, the general notion of function becomes a notion of fundamental importance for Dedekind, and this is reflected again in a terminological change: functions become mappings (Abbildung). The first occurrence of the term

\footnotetext{
${ }^{36}$ In his [1996], Corry emphasizes this difference in the way Dedekind thinks of groups and fields in order to support his claim that Dedekind did not have a 'structuralist view' of these mathematical objects.

${ }^{37}$ Stillwell translates 'permutation' as 'isomorphism' in [Dedekind, 1996, p. 108]. The terminology used in 1877 is incorporated also in supplements to the third [1879] and fourth [1894] editions of Dirichlet's lectures. In 1894 Dedekind defines a permutation as a substitution between fields, such that 'alle zwischen den Zahlen $a$ bestehenden rationalen Beziehungen sich vollständig auf die Bilder $a^{\prime}$ übertragen' [Dirichlet, 1894, p. 457].

38 [Dedekind, 1996, p. 109]. The French text in [Dedekind, 1877, p. 152]. is: '[ $\ldots$ ] par une permutation, deux nombres différents $\alpha, \beta$ du corps $\Omega$, se changeront aussi en deux nombres différents $\alpha^{\prime}, \beta^{\prime}$, du corps $\Omega^{\prime}$, et qu'ainsi chaque nombre détermine $\alpha^{\prime}$ du corps $\Omega^{\prime}$ ne correspond qu'à un seul nombre complètement déterminé $\alpha$ du corps $\Omega$. La correspondance peut donc être renversée d'une manière univoque.'
} 
'mapping' in Dedekind's published writings appears in the third edition of Dirichlet's lectures on number theory of 1879 , where he elaborates on the general concept of substitution he had introduced two years earlier in the French essay:

It happens very frequently in mathematics and in other sciences, that if a system $\Omega$ of things or elements $\omega$ is given, every particular element $\omega$ is replaced by a corresponding particular element $\omega^{\prime}$ according to a certain law; such an act is commonly called a substitution and we say that by this substitution the element $\omega$ passes over into the element $\omega^{\prime}$, and similarly the system $\Omega$ into the system $\Omega^{\prime}$. This terminology becomes even a bit more convenient if one considers this substitution as a mapping of the system $\Omega$, and accordingly $\omega^{\prime}$ the image of $\omega$, and $\Omega^{\prime}$ the image of $\Omega$ - which is what we intend to do. ${ }^{39}$

In a footnote to this passage Dedekind also announces the publication of WZ with a striking general programmatic claim:

As I will try to show in a different place, the entire science of numbers is also based on this ability of the mind to compare a thing $\omega$ with a thing $\omega^{\prime}$, or to relate $\omega$ to $\omega^{\prime}$, or to make $\omega$ correspond to a $\omega^{\prime}$, without which no thinking is possible at all. ${ }^{40}$

We know that at the time of this announcement Dedekind already was in possession of an extensive draft for WZ, i.e., [Dedekind, 1872/78]. In this draft the term 'mapping' (Abbildung) is introduced in his analysis of the process of counting and as synonymous to 'correspondence':

If one tracks exactly what we do when counting the set or the number of things, one is necessarily led to the concept of correspondence or mapping. ${ }^{41}$

${ }^{39}$ [Dirichlet, 1879, p. 470]. Neglecting the fact that Dedekind's conception of substitution changed, Ferreirós quotes this passage to confirm his claim that the notion of 'substitution' Dedekind used already in his lectures notes on algebra essentially means 'mapping' [Ferreirós, 2007, p. 89]. The German text is: 'Es geschieht in der Mathematik und in anderen Wissenschaften sehr häufig, dass, wenn ein System $\Omega$ von Dingen oder Elementen $\omega$ vorliegt, jedes bestimmte Element $\omega$ nach einem gewissen Gesetze durch ein bestimmtes, ihm entsprechendes Element $\omega^{\prime}$ ersetzt wird; einen solchen Act pflegt man eine Substitution zu nennen, und man sagt, dass durch diese Substitution das Element $\omega$ in das Element $\omega^{\prime}$, und ebenso das System $\Omega$ in das System $\Omega^{\prime}$ übergeht. Die Ausdrucksweise gestaltet sich noch etwas bequemer, wenn man, was wir thun wollen, diese Substitution wie eine Abbildung des Systems $\Omega$ auffasst und demgemäss $\omega^{\prime}$ das Bild von $\omega$, ebenso $\Omega^{\prime}$ das Bild von $\Omega$ nennt.'

${ }^{40}$ [Dirichlet, 1879, p. 470] The German text is: 'Auf dieser Fähigkeit des Geistes, ein Ding $\omega$ mit einem Ding $\omega^{\prime}$ zu vergleichen, oder $\omega$ auf $\omega^{\prime}$ zu beziehen, oder dem $\omega$ ein $\omega^{\prime}$ entsprechen zu lassen, ohne welche ein Denken überhaupt nicht möglich ist, beruht, wie ich an einem anderen Orte nachzuweisen vesuchen werde, auch die gesamte Wissenschaft der Zahlen.'

${ }^{41}$ [Dugac, 1976, LVI, p. 293] The German text is: 'Verfolgt man genau, was wir beim Abzählen der Menge oder Anzahl von Dingen thun, so wird man nothwendig auf den Begriff der Correspondenz oder Abbildung geführt.' 
On 2 July 1877, Dedekind writes to Cantor about a continuous correspondence (Correspondenz) between the points of two manifolds, and Cantor uses the same term in his replies. On 29 December 1878, Cantor mentions two articles which both contain the phrase 'Abbildung von Mannigfaltigkeiten' in the title [Jürgens, 1878; Lüroth, 1878 ], and on 17 January 1879 Cantor writes about an 'eindeutige und stetige Abbildung von Mannigfaltigkeiten'. In his reply of 19 January 1879, Dedekind again uses the verb 'to correspond' to express the relation between two points, but also speaks of a mapping between spheres around these points; ${ }^{42}$ see [Noether and Cavaillès, 1937, p. 44]. Indeed, in geometry it was fairly common to speak of an Abbildung between various geometric objects as we saw with reference to Gauss above in the Introduction. ${ }^{43}$ Klein $[1871$, p. 573] even called the interpretation of a geometry an image (Bild). The application of this term was then extended from geometric manifolds to manifolds in general. In an attempt to clear up a confusion in Keferstein's understanding of the two central notions of mapping (Abbildung) and image (Bild), Dedekind adds to mapping in parenthesis 'the mapping painter' (der abbildende Maler); this addition is to illustrate the difference between the two notions [van Heijenoort, 1967, p. 102]. The vivid association with the term seems to have appealed to Dedekind: when introducing 'mapping' as a different expression for 'substitution' in [Dirichlet, 1894, p. 456] he notes that this makes the formulations 'more convenient and more intuitive'. ${ }^{4}$

In the 1872/78 draft of WZ, Dedekind defines and studies the notion of mapping in a way that is very close to the later publication. For example, in the first (and presumably earlier) part of this draft Dedekind writes:

Mapping $\phi$ of the system $A$ into the system $B$. To every thing $a$ of $A$ corresponds ( $a$ determines) a thing $a \mid \phi=b$ of the system $B$.

Clarity of a mapping $\phi: a^{\prime} \mid \phi$ and $a^{\prime \prime} \mid \phi$ are mapped differently, if $a^{\prime}, a^{\prime \prime}$ different. $^{45}$

Later in the notes, a more eloquently formulated definition of mappings is given that is almost exactly like the one given in Section 21 of WZ. ${ }^{46}$ Notice how Dedekind's notion of mapping is closely connected to his notion of system, which emerged in its

\footnotetext{
${ }^{42}$ This is Dedekind's first and only use of Abbildung we could find in the correspondence with Cantor.

${ }^{43}$ Apart from Gauss's use of this term, it is also employed in [Riemann, 1851, p. 5] and [Schröder, 1873], for example there on p. 6.

${ }^{44}$ The fuller German text: 'Die Ausdrucksweise gestaltet sich noch etwas bequemer und anschaulicher, wenn man, was wir tun wollen, diese Substitution wie eine Abbildung des Systems $A$ auffasst und demgemäss $a^{\prime}$ das Bild von $a$, ebenso $A^{\prime}$ das Bild von $A$ nennt.'

45 [Dugac, 1976, LVI, p. 294]. The German text is: 'Abbildung $\phi$ des Systems $A$ in dem System $B$. Jedem Ding $a$ des $A$ entspricht (durch $a$ ist bestimmt) ein Ding $a \mid \phi=b$ des System $B$.

Deutlichkeit einer Abbildung $\phi: a^{\prime} \mid \phi$ und $a^{\prime \prime} \mid \phi$ verschieden abgebildet, wenn $a^{\prime}, a^{\prime \prime}$ verschieden.'

46 [Dugac, 1976, pp. 304-305]. Here is the German text to make the comparison with the formulation in WZ easy: 'Unter einer Abbildung $\phi$ eines Systems $S$ wird ein Gesetz verstanden, nach welchem aus jedem bestimmten in $S$ enthaltenen Ding $a$ ein bestimmtes Ding erzeugt wird, welches das Bild von $a$ heissen und mit $a \mid \phi$ bezeichnet werden soll. [... ] Die Abbildung $\phi$ des Systems $S$ heisst deutlich, wenn die Bilder $a|\phi, b| \phi$ von verschiedenen in $S$ enthaltenen Dingen $a, b$ stets verschieden sind.'
} 
full generality also at this time. Indeed, for Dedekind all human thinking is based on these two notions. The indispensability of the notions of system and mapping for the development of the theory of arithmetic is emphasized for the first time in the draft to WZ [Dugac, 1976, p. 293]; it is then extended to thinking in general in Supplement XI of [Dirichlet, 1879] and is again emphasized in [1894] referring to the earlier remark; see the quotation in our Introduction.

Beginning with the first draft of WZ, mappings or general substitutions are no longer just treated as a tool for studying algebraic structures, but explicitly become objects of investigation in their own right; indeed, they now form a second category of central mathematical objects. Their fundamental importance for Dedekind's treatment of the natural numbers is clearly visible in WZ. In $\$ 2$ of WZ Dedekind explains that mappings do not necessarily have to have numbers as their domain and range, and that the domain can be of a different sort than the range. He mentions the mapping from elements of a system to their names as an example [Dedekind, 1888, p. 348]. In a footnote to this explanation, Dedekind refers to the passage on p. 470 of the 1879 edition of Dirichlet's lectures quoted above. In the 1894 edition of these lectures, Dedekind explicitly refers to the terminology of WZ [Dirichlet, 1894, p. 458] and notes that the composition of permutations is a special case of the composition of mappings between arbitrary systems that he discussed in WZ [Dirichlet, 1894, p. 461].

Dedekind's mappings $\varphi$ of a system $S$, despite their seeming generality, are defined in WZ as a 'law according to which to every determinate element $s$ of $S$ there belongs a determinate thing which is called the transform of $s$ and denoted $\varphi(s)$.' $\varphi(s)$ is said to 'correspond to $s$ ' or ' $s$ is transformed into $\varphi(s)$ '. But what is a law? - Gauss, as we saw above in our Introduction, used the same terminology when specifying Abbildungen in 1825, and Hilbert asked our question in 1905, when thinking about the genetic method and the definition of real numbers as systems of infinitely many numbers:

Must this number sequence be subject to a law, and what is a law? Is an irrational number being defined, if given by throwing dice? These are the kinds of questions with which the genetic perspective has to be confronted. ${ }^{47}$

In any event, this points to a conceptual issue that was resolved only by Zermelo in his [1908]. His investigations are existential axiomatic ones in the spirit of Dedekind and Hilbert; see the set-up in [van Heijenoort, 1967, p. 201]. Set theory has for him the task 'to investigate mathematically the fundamental notions number, ordering, and function, taking them in their pristine, simple form, and to develop thereby the logical foundations of all of arithmetic and analysis; ... '48 In this way, Zermelo claims, 'it [set theory] constitutes an indispensable component of the science of mathematics.'

47 [Hilbert, 1905, pp. 10-11]. The German text is found in [Sieg, 2009, p. 334].

48 [Zermelo, 1908] in [van Heijenoort, 1967, p. 200]. The fuller German text is: 'Die Mengenlehre ist derjenige Zweig der Mathematik, dem die Aufgabe zufällt, die Grundbegriffe der Zahl, der Anordnung und der Funktion in ihrer ursprünglichen Einfachheit mathematisch zu untersuchen und damit die logischen Grundlagen der gesamten Arithmetik und Analysis zu entwickeln; sie bildet somit einen unentbehrlichen Bestandteil der mathematischen Wissenschaft.' 
Zermelo does not introduce functions, but rather mappings (Abbildungen) that really are set-theoretic representations of bijections. Mappings are used to develop Cantor's theory of equivalences, thus to compare the size of sets, and lead up to the Cantor-Bernstein theorem and Cantor's theorem; they are defined, only for disjoint sets $M$ and $N$, as subsets of Zermelo's product of unordered pairs of elements from $M$ and $N$. (These subsets must of course satisfy the usual conditions for bijections.) Zermelo's treatment of this elementary part of set theory is quite cumbersome from a contemporary perspective accustomed to the immediate introduction of ordered pairs. However, Zermelo frees mappings from any association with laws and obtains them as purely set-theoretic objects. As if to emphasize the origin of this notion, Zermelo introduces Dedekind's terminology for mappings: for two elements that are mapped onto each other he says that they 'correspond to each other' or that 'one is the image of the other'.

\section{CONCLUSION: METHODOLOGICAL DIRECTIONS}

Let us return to Dedekind and complement the broad context of a mathematical kind that we described at the beginning of our paper by a more philosophical one. This will be grounded in the developments analyzed above: Section 1 discussed the evolution of Dedekind's axiomatic standpoint ending with the idea of an abstract concept (or a structural definition or an axiom system); Section 2 showed Dedekind arriving at mappings that preserve structure and do so independently of the nature of the objects in the corresponding systems. Dedekind's first draft of WZ from 1872-78 is evidence of an emerging framework used later to formulate that an abstract concept can determine its models uniquely up to isomorphism. ${ }^{49}$

Dedekind's presentation in WZ is the endpoint of a long development of methodological reflection and mathematical work. The starting-point of this development, in published accounts, can be seen in [Dirichlet, 1871] and SZ of 1872. With the perspective on Dedekind's work we have gained, we can circle back to the beginning and arrive at a deepened understanding of SZ. We analyzed SZ in Section 1 and remarked that a real connection between different ordered systems is adumbrated, but not yet fully conceptualized. What was missing? Actually, two things were missing, namely, the abstract concept of a continuous ordered system on the one hand and the general concept of mapping on the other hand. Using them and Dedekind's explicit, though informal way of 'connecting' the geometric line with the system of all cuts of rational numbers, one can easily prove that those two continuous ordered systems are isomorphic. It is in this sense that we understand Dedekind's remark about 'the perfect pattern' of a continuous domain in his letter of 10 June 1876 to Lipschitz:

\footnotetext{
${ }^{49}$ Just to re-emphasize a point made in the earlier fn. 17: particular systems that fall under an abstract concept can be viewed as 'models'. That corresponds to current mathematical practice, say, when giving examples that satisfy the axioms for groups, but also to earlier logical practice. A wonderful summary of how Dedekind saw this development from an 'analysis of the sequence of natural numbers just as it presents itself, in experience, so to speak' to the abstract notion of a simply infinite system is found in his letter to Keferstein, i.e., [Dedekind, 1890]. See also the discussion of this passage in [Schlimm, 2013, pp. 58-59].
} 
After all this I continue to claim that the Euclidean principles alone - without the addition of the continuity principle that is not implied by them - are incapable of grounding a complete theory of real numbers as ratios of magnitudes. ... Conversely and in contrast, my theory of irrational numbers creates the perfect pattern of a continuous domain that is capable [on account of its continuity] of characterizing every ratio of magnitudes by a determinate number-individual that is contained in it [the domain]. ${ }^{50}$

From our perspective then, Dedekind can be taken to show in SZ that the system of cuts of rational numbers falls under the abstract concept of a continuous ordered system and that it is isomorphic to the geometric line. As a matter of fact, Dedekind indicates in Section VI, entitled 'Operations with real numbers', that the system of cuts forms a complete ordered field.

For natural numbers and their unique characterization, Dedekind took a decisive step in [Dedekind, 1887], the penultimate draft of WZ, when he introduced the abstract concept of a simply infinite system in \#50 and used it to replace the discussion of a particular system; see the end of Section 1. This concept does not depend on particular objects, but declares any system $N$ of things to be simply infinite if there is a similar function $\phi$ from $N$ to a proper subset, such that $N$ is the chain of an element not in the $\phi$-image of $N$. This structural definition for arbitrary systems is the decisive, critical step. In a note associated with these modified considerations, Dedekind proposed to expand the brief remark 107 that concluded the manuscript. He had formulated as '102. Satz' the recursion theorem and as '106. Satz' the fact that all simply infinite systems are isomorphic. The proof of the last theorem is followed by Remark 107:

Creation of the pure natural numbers. It follows from the above that the laws regarding the relations between numbers are completely independent of the choice of that simply infinite system $N$, which we have called the sequence of numbers, as well as independent of the mapping from $N$, by which $N$ is ordered as a simple sequence. ${ }^{51}$

Unfortunately, we do not have the promised expansion in manuscript form, but the substantive issues are treated in Section 10 of WZ. Before we discuss that section, let

50 [Dedekind, 1932, p. 474]. The German text is: 'Nach allem diesem bleibe ich bei meiner Behauptung, dass die Euklidischen Principien allein, ohne Zuziehung des Principes der Stetigkeit, welches in ihnen nicht enthalten ist, unfähig sind, eine vollständige Lehre von den reellen Zahlen als den Verhältnissen der Grössen zu begründen; ... Umgekehrt aber wird durch meine Theorie der irrationalen Zahlen das vollkommene Muster eines stetigen Gebietes erschaffen, welches eben deshalb fähig ist, jedes Grössen-Verhältnis durch ein bestimmtes in ihm enthaltenes Zahl-Individuum zu charakterisieren.'

51 [Dedekind, 1887, p. 19]. The German text is: 'Schöpfung der reinen natürlichen Zahlen. Aus dem Vorhergehenden ergiebt sich, dass die Gesetze über die Beziehungen zwischen den Zahlen gänzlich unabhängig von der Wahl desjenigen einfach unendlichen Systems $N$ sind, welches wir die Zahlenreihe genannt haben, sowie auch unabhängig von der Abbildung von $N$, durch welche $N$ als einfache Reihe geordnet ist.' 


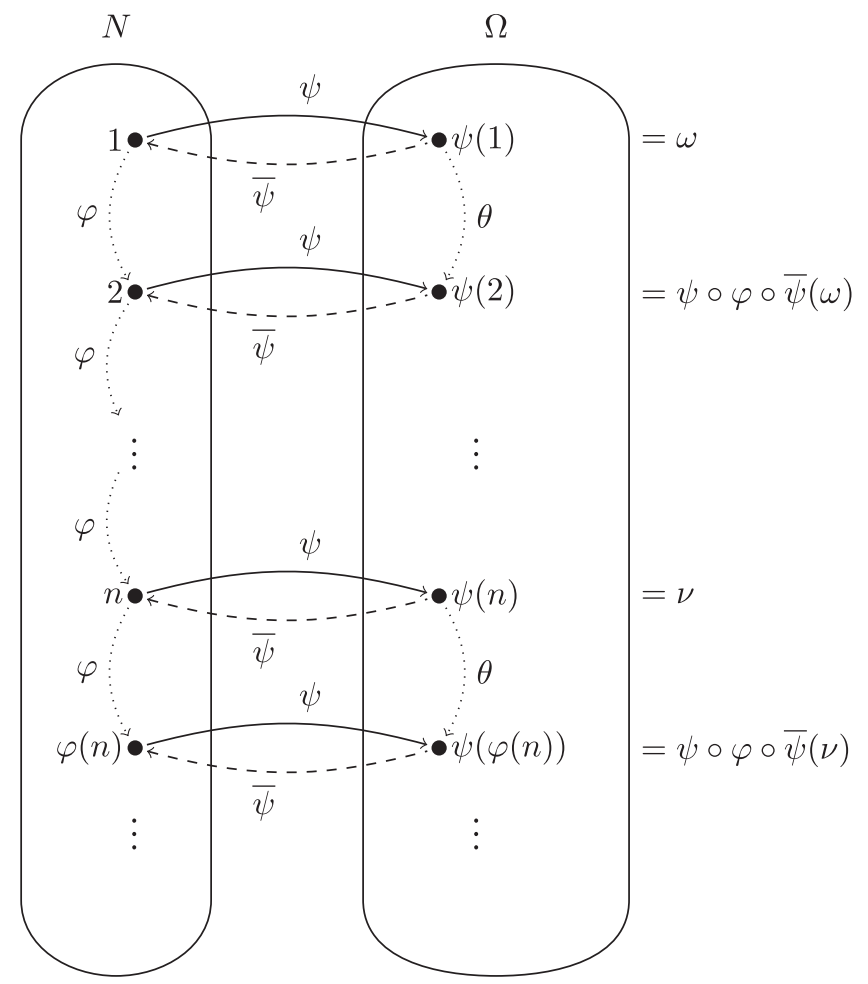

Fig. 2. $\psi$ is the similar mapping from $N$ to $\Omega$ with $\psi(N)=\Omega$. The 'new' simply infinite system is $\Omega$ with $\omega$ and $\theta$, where $\theta(v)=\psi \circ \varphi \circ \bar{\psi}(v)$.

us notice that Dedekind now views the laws to be not only independent of the choice of the initial element and the ordering function, but also of the system $N$.

Section 10 is titled 'The class of simply infinite systems' and consists of two theorems (\#132 and \#133) followed by a most significant remark, \#134. Theorem 132 contains the manuscript's claim 106, which is obtained now as an immediate consequence of a proper Representation Theorem: Every simply infinite system is similar to the number system $N .^{52}$ The converse of this theorem is then formulated as theorem 133, namely, if a system $\Omega$ is similar (to some simply infinite system and, thus, by \#132) to $N$, then it is simply infinite. More precisely, if the mapping $\psi$ guarantees the similarity of $\Omega$ and $N$, then it can be used to define a distinguished element $\omega$ of $\Omega$ and a similar mapping $\theta$ on $\Omega$, such that $\Omega$ together with $\omega$ and $\theta$ is indeed a simply infinite system. (See Figure 2.) This direct way of transporting the ordering from $N$ to $\Omega$ must have been striking even for Dedekind.

Dedekind introduced in \#34 of WZ a notion that is not found in the manuscript, namely, that of a 'class' (Klasse). ${ }^{53}$ According to theorems 132 and 133, the class of the

\footnotetext{
${ }^{52}$ This is the system of natural numbers chosen in \#73.

53 'Klasse' is introduced in WZ as follows. First, the relation of similarity between systems is introduced in \#32. (Two systems are similar, in modern terminology, if there is a bijection between them.)
} 
systems similar to $N$ consists of all and only simply infinite systems. This mathematical fact is formulated in the first sentence of Remark 134 and serves as one of two pillars for the complete justification of the concept of natural number given in \#73. The other pillar, formulated already in \#73, is the restriction to use in proofs apart from 'logic' only appeals to the characteristic conditions for the simply infinite system $N$ as stipulated in \#71. Together, they support Dedekind's argument that $N$ is elementarily equivalent to any other simply infinite system: every theorem for the elements of $N$ has general validity (allgemeine Gültigkeit) for those of any other simply infinite system. Dedekind's 'indifference to identification', using Burgess's apt phrase, ${ }^{54}$ is ultimately grounded in a mathematical fact: the mapping $\psi$ between $N$ and $\Omega$ transforms (verwandelt) the elements in $N$ into elements in $\Omega$, but it also transforms the mapping $\varphi$ that orders $N$ into the mapping $\theta$ that orders $\Omega$. Mappings are thus absolutely central for Dedekind's reflections on natural numbers (in \#71, \#73, and \#134 of WZ). 55

The work in WZ is strategically connected with the goal of providing an arithmetical grounding of analysis and, thus, of geometry. In the Introduction to WZ, Dedekind emphasizes, it is only through the creation of the 'pure, continuous realm of numbers' that we have obtained 'the means to transform the concept of continuous space to a definite one' (WZ, p. VIII). Dedekind's considerations concerning the 'indifference of identification' were, in a certain way, rounded off and completed by Hilbert in Grundlagen der Geometrie and Über den Zahlbegriff. In the former, Hilbert defines directly the structural notion of Euclidean space; in the latter, he introduces the abstract notion of a complete ordered field as an axiomatization for analysis. For him, there is no intention of assigning priority to either geometry or arithmetic: indeed, Hilbert gives an analytic model for Euclidean geometry and constructs a geometric one for the arithmetic of real numbers. ${ }^{56}$

In Dedekind's work, fundamental concepts not only emerge from reflective investigations of mathematical practice but are also affecting it deeply. Under this perspective, Herbart's remark that we used as a motto for our earlier paper gains a particular poignancy: 'Treated philosophically, it [mathematics] becomes a part of philosophy.' 57

Then, in \#33, the transitivity of that relation is established; it is of course also reflexive and symmetric. That is taken as the ground for 'separating all systems into classes': considering a particular system $R$, the systems similar to $R$ form a determinate class with $R$ as its representative. Dedekind remarks that 'the class is not changed by taking as a representative any other system belonging to it'. - Note the similarity of these deliberations with those concerning fields and 'being conjugate of described at the end of 2.1 above.

${ }^{54}$ [Burgess, 2011, p. 8].

${ }^{55}$ Hilbert made the general point in his correspondence with Frege when explaining why a theory can only be a framework (Fachwerk) or schema of concepts: '... eine jede Theorie kann stets auf unendlich viele Systeme von Grundelementen angewandt werden. Man braucht ja nur eine umkehrbar eindeutige Transformation anzuwenden und festzusetzen, dass die Axiome für die transformirten Dinge die entsprechend gleichen sein sollen.' [Frege, 1980, p. 13]

${ }^{56}$ This geometric model is presented in chapter III of Grundlagen der Geometrie.

${ }^{57}$ One central aspect of Dedekind's considerations is directly connected to philosophy and, in particular, to traditional logic: the creation of new concepts (die Schöpfung neuer Begriffe) that was crucial already in his Habilitationsrede of 1854 . Two kinds of abstractions seem to be appealed to: one 


\section{REFERENCES}

Beltrami, Eugenio [1868]: 'Saggio di interpretazione della geometria non-euclidea', Giornale di Matematica 6, 284-312. English translation in [Stillwell, 1996], pp. 7-34.

Bourbaki, Nicolas [1994]: Elements of the History of Mathematics. Berlin, Heidelberg, and New York: Springer Verlag. (The original French edition was published in 1984).

Burgess, J.P. [2011]: 'Structure and rigor', talk at Oxford University, 20 pp.

Cantor, Georg [1872]: 'Ueber die Ausdehnung eines Satzes aus der Theorie der trigonometrischen Reihen', Mathematische Annalen 5, 123-132.

Cauchy, Augustin [1815]: 'Mémoire sur le nombre des valeurs qu'une fonction peut acquérir, lorsqu'on y permute de toutes les manières possibles les quantités qu'elle renferme', Journal de l'École Polytechnique XVII, 1-28. Reprinted in Euvres complètes de Augustin Cauchy, Série 2, Tome 1 (1905), pp. 64-90.

[1844]: 'Mémoire sur les arrangements que l'on peut former avec des lettres données, et sur les permutations ou substitutions à l'aide desquelles on passe d'un arrangement à un autre', Exercises d'Analyse et de Mathématiques Physiques III, 152-242. Reprinted in Ouvres complètes de Augustin Cauchy, Série 2, Tome 13 (1933), pp. 171-282.

Corry, Leo [1996]: Modern Algebra and the Rise of Mathematical Structures, Vol. 17 of Science Networks. Historical Studies. 2nd rev. ed., 2004. Basel: Birkhäuser.

Dedekind, Richard [1854]: Über die Einführung neuer Funktionen in der Mathematik, Habilitationsvortrag, in [Dedekind, 1932], pp. 428-438. English translation On the introduction of new functions in mathematics by William Ewald in [Ewald, 1996], pp. 754-762.

[1855-58]: Aus den Gruppen-Studien (1855-58), in [Dedekind, 1932], Chapter LXI, pp. 439-445.

[1872]: Stetigkeit und irrationale Zahlen. Braunschweig: Vieweg. Reprinted in [Dedekind, 1932], pp. 315-334. English translation Continuity and Irrational Numbers by Wooster W. Beman, revised by William Ewald, in [Ewald, 1996], pp. 765-779.

[1872/78]: 'Was sind und was sollen die Zahlen? (Erster Entwurf 1872-1878)', Niedersächsische Staats- und Universitätsbibliothek, Göttingen, Cod. Ms. Dedekind III, 1:I. Printed in [Dugac, 1976], pp. 293-309.

[1877]: Sur la théorie des nombres entiers algébriques. Paris: Gauthier-Villars. Introduction and Sections I-II reprinted in [Dedekind, 1932], pp. 262-296. English translation of the Introduction by David Reed in [Ewald, 1996], pp. 779-787. English translation of the entire text by John Stillwell in [Dedekind, 1996].

— [1887]: 'Was sind und was sollen die Zahlen?' Manuscript, third version. Niedersächsische Staats- und Universitätsbibliothek, Göttingen, Cod. Ms. Dedekind, III, 1.

leads to abstract concepts as paradigmatically described in Section 1 for the concept of simply infinite systems; the other leads to abstract objects as in Dedekind's manuscript [1887]. The latter is best understood, however, as a traditional form of conceptual abstraction - without the need to introduce abstract objects, but rather having familiar objects fall under 'more abstract' concepts. This kind of 'abstraction from' is described in Kant's Logik [1800] (\$6 of the Elementarlehre, A 145-148). The 'more abstract' concepts are obtained through leaving out, or abstracting from, some characteristic conditions or Merkmale. The other abstraction was emphasized in Lotze's Logik [1874] and [1989] ( $\$ 23$ of the first chapter, Die Lehre vom Begriffe). In this abstraction Merkmale are usually not left out, but rather replaced by more general ones - exactly what is done in WZ when introducing the notion of a simply infinite system. Thus, Lotze's abstraction contains the Kantian one as a special case. These are two different kinds of conceptual abstraction, and both forms are radically different from the abstraction used by Frege and Neo-logicists. The latter is, in Kantian terminology, 'abstraction to'. That is made marvelously clear in Chapter 1, Philosophical Introduction, of [Fine, 2002]. 
[1888]: Was sind und was sollen die Zahlen? Braunschweig: Vieweg. Reprinted in [Dedekind, 1932], pp. 335-391. English translation by Wooster W. Beman, revised by William Ewald, in [Ewald, 1996], pp. 787-833.

[1890]: Letter to Keferstein. Published in German in [Sinaceur, 1974], pp. 270-278. An English translation is found in [van Heijenoort, 1967], pp. 98-103.

_ [1931]: Gesammelte mathematische Werke, Vol. 2. Robert Fricke, Emmy Noether, and Öystein Ore. eds. Braunschweig: Vieweg.

_ [1932]: Gesammelte mathematische Werke, Vol. 3. Robert Fricke, Emmy Noether, and Öystein Ore. eds. Braunschweig: Vieweg.

— [1996]: Theory of Algebraic Integers. English translation of [Dedekind, 1877]. Translated and introduced by John Stillwell. Cambridge: Cambridge University Press.

Dieudonné, Jean [1970]: 'The work of Nicolas Bourbaki'. American Mathematical Monthly 77, 134145.

Dirichlet, P.G. Lejeune [1863]: Vorlesungen über Zahlentheorie, Hrsg. und mit Zusätzen versehen von R. Dedekind. 1st ed. Braunschweig: Vieweg.

- [1871]: Vorlesungen über Zahlentheorie, Hrsg. und mit Zusätzen versehen von R. Dedekind. 2nd ed. Braunschweig: Vieweg.

- [1879]: Vorlesungen über Zahlentheorie, Hrsg. und mit Zusätzen versehen von R. Dedekind. 3rd ed. Braunschweig: Vieweg.

- [1889]: Werke, Vol. 1. Leopold Kronecker, ed. Reprinted as part of the Chelsea edition of both volumes, New York, 1969.

— [1894]: Vorlesungen über Zahlentheorie, Hrsg. und mit Zusätzen versehen von R. Dedekind, 4th ed. Braunschweig: Vieweg.

Dugac, Pierre [1976]: Richard Dedekind et les fondements des mathématiques (avec de nombreux textes inédits). Paris: Vrin.

Ewald, William [1996]: From Kant to Hilbert: A Source Book in the Foundations of Mathematics. Two volumes. Oxford: Clarendon Press.

Ewald, William, and Wilfried Sieg, eds [2013]: David Hilbert's Lectures on the Foundations of Arithmetic and Logic, 1917-1933, Vol. 3 of David Hilbert's Lectures on the Foundations of Mathematics and Physics, 1891-1933. In collaboration with Michael Hallett, Ulrich Majer, and Dirk Schlimm. Berlin, Heidelberg, and New York: Springer.

Ferreirós, José [2007]: Labyrinth of Thought: A History of Set Theory and Its Role in Modern Mathematics. 2nd ed. Basel, Switzerland: Birkhäuser.

Fine, Kit [2002]: The Limits of Abstraction. Oxford: Clarendon Press.

Frege, Gottlob [1980]: Gottlob Freges Briefwechsel mit D. Hilbert, E. Husserl, B. Russell, sowie ausgewählte Einzelbriefe Freges. Philosophische Bibliothek, No. 321, Gottfried Gabriel, Friedrich Kambartel, and Christian Thiel, eds. Hamburg: Felix Meiner.

Gauss, Carl Friedrich [1825a]: 'Allgemeine Auflösung der Aufgabe die Theile einer gegebenen auf einer andern gegebenen Fläche so abzubilden dass die Abbildung dem Abgebildeten in den kleinsten Theilen ähnlich wird'. Reprinted in vol. IV of his Werke (1873), pp. 189-216.

[1825b]: Letter to Hansen of 11 December 1825, in vol. XII of his Werke (1929), pp. 6-9.

Gödel, Kurt [1929]: Über die Vollständigkeit des Logikkalküls. PhD thesis, University of Vienna. Reprinted in [Gödel, 1986], pp. 60-101.

— [1986]: Collected Works I - Publications 1929-1936. Solomon Feferman et al., eds. Oxford: Oxford University Press.

Hallett, Michael, and Ulrich Majer, eds [2004]: David Hilbert's Lectures on the Foundations of Geometry 1891-1902, Vol. 1 of David Hilbert's Lectures on the Foundations of Mathematics and Physics, 1891-1933. Berlin, Heidelberg, and New York: Springer.

Hilbert, David [1899]: Grundlagen der Geometrie. Leipzig: Teubner. Reprinted in [Hallett and Majer, 2004], pp. 436-525. 
[1900]: 'Über den Zahlbegriff, Jahresbericht der Deutschen Mathematiker Vereinigung 8, 180-

194. Reprinted as Anhang VI in Grundlagen der Geometrie, 3rd ed., Leipzig, 1909, pp. 256-261.

[1905]: 'Über die Grundlagen der Logik und der Arithmetik', in Verhandlungen des Dritten Internationalen Mathematiker-Kongresses, pp. 174-185. Leipzig: Teubner. Address delivered on 12 August 1904 at the Third International Congress of Mathematicians, held in Heidelberg on 8-13 August 1904. English translation: 'On the foundations of logic and arithmetic', by Beverly Woodward in [van Heijenoort, 1967], pp. 129-138.

— [1917/18]: Prinzipien der Mathematik. Niedersächsische Staats- und Universitätsbibliothek, Göttingen, Mathematisches Institut, Inv. Nr. 6817a. Reprinted in [Ewald and Sieg, 2013], pp. 59-214.

Hilbert, David, and Wilhelm Ackermann [1928]: Grundzüge der theoretischen Logik. Berlin: Springer. Reprinted in [Ewald and Sieg, 2013], pp. 806-915.

Jürgens, Enno [1878]: 'Ueber eindeutige und stetige Abbildung von Mannigfaltigkeiten', Tageblatt der 51. Versammlung Deutscher Naturforscher und Aerzte in Cassel, pp. 137-140.

Kant, Immanuel [1800]: Immanuel Kants Logik ein Handbuch zu Vorlesungen. Königsberg: Nicolovius. Reprinted in Immanuel Kant Werke in sechs Bänden. Vol. III. W. Weischedel, ed., pp. 419-582. Darmstadt: Wissenschaftliche Buchgesellschaft, 1975.

Keferstein, Hans [1890]: 'Über den Begriff der Zahl', in Festschrift der Mathematischen Gesellschaft in Hamburg, pp. 119-125. Leipzig: Teubner.

Klein, Felix [1871]: 'Ueber die sogenannte Nicht-Euklidische Geometrie', Mathematische Annalen 4, 573-625. Reprinted in [Klein, 1921], ch. 16, pp. 254-305.

- [1921]: Gesammelte mathematische Abhandlungen, Vol. 1. R. Fricke and A. Ostrowski, eds, with additions by F. Klein. Berlin: Springer.

Klev, Ansten [2011]: 'Dedekind and Hilbert on the foundations of the deductive sciences', Review of Symbolic Logic 4, 645-681.

Lotze, Hermann [1874]: Logik. Drei Bücher vom Denken, vom Untersuchen und vom Erkennen. Leipzig: Verlag von G. Hirzel.

— [1989]: Logik. Erstes Buch. Vom Denken (reine Logik). Gottfried Gabriel, ed. Hamburg: Meiner Verlag.

Lüroth, Jakob [1878]: 'Über gegenseitig eindeutige und stetige Abbildung von Mannigfaltigkeiten verschiedener Dimensionen aufeinander', Sitzungsber. d. phys.-medic. Societät zu Erlangen 10, 190-195.

Monna, A.F. [1972]: 'The concept of function in the 19th and 20th centuries, in particular with regard to the discussions between Baire, Borel and Lebesgue', Archive for History of Exact Sciences 9, 57-84.

Noether, Emmy, and Jean Cavaillès, eds [1937]: Briefwechsel Cantor-Dedekind. Actualités Scientifiques et Industrielles, No. 518. Paris: Hermann.

Riemann, Bernhard [1851]: Grundlagen für eine allgemeine Theorie der Functionen einer veränderlichen complexen Grösse. Dissertation, Göttingen. Reprinted in [Riemann, 1892], pp. 3-43.

_ [1854]: 'Über die Hypothesen, welche der Geometrie zu Grunde liegen', Abhandlungen der Königlichen Gesellschaft der Wissenschaften zu Göttingen 13 (1868). Reprinted in [Riemann, 1892], pp. 272-287. English translation in [Ewald, 1996], vol. 2, pp. 652-661.

[1892]: Gesammelte mathematische Werke und wissenschaftlicher Nachlass. Leipzig: Teubner. 2nd ed. Heinrich Weber, ed, with the assistance of Richard Dedekind. First edition 1876, with different pagination. Reprinted New York: Dover (1953).

Scharlau, Winfried, ed. [1981]: Richard Dedekind, 1831-1981. Eine Würdigung zu seinem 150. Geburtstag. With contributions by Ilse Dedekind, Pierre Dugac, Wulf-Dieter Geyer, and Winfried Scharlau. Braunschweig: Vieweg.

Schlimm, Dirk [2008]: 'Two ways of analogy: Extending the study of analogies to mathematical domains', Philosophy of Science 75, 178-200.

[2011]: 'On the creative role of axiomatics: The discovery of lattices by Schröder, Dedekind, Birkhoff, and others', Synthese 183, 47-68. 
_ [2013]: 'Axioms in mathematical practice', Philosophia Mathematica (3) 21, 37-92.

Schröder, Ernst [1873]: Lehrbuch der Arithmetik und Algebra für Lehrer und Studierende, Vol. 1: Die sieben algebraischen Operationen. Leipzig: Teubner.

Sieg, Wilfried [2009]: 'Hilbert's proof theory', in Dov M. Gabbay and John Woods, eds, Handbook of the History of Logic, Vol. 5, pp. 321-384. Amsterdam: Elsevier.

- [2013]: Hilbert's Programs and Beyond. Oxford: Oxford University Press.

[2014]: 'The ways of Hilbert's axiomatics: Structural and formal', Perspectives on Science 22, $133-157$.

Sieg, Wilfried, and Rebecca Morris [2014]: 'Dedekind's structuralism: Creating concepts and making derivations'. In preparation.

Sieg, Wilfried, and Dirk Schlimm [2005]: 'Dedekind's analysis of number: Systems and axioms', Synthese 147, 121-170.

Sinaceur, M.A. [1974]: 'L'infini et les nombres — Commentaires de R. Dedekind à 'Zahlen' — La correspondance avec Keferstein', Revue d'historie des sciences 27, 251-278.

Stillwell, John [1996]: Sources of Hyperbolic Geometry. History of Mathematics, vol. 10. Providence, R.I.: American Mathematical Society.

van Heijenoort, Jean [1967]: From Frege to Gödel: A Sourcebook of Mathematical Logic. Cambridge, Massachusetts: Harvard University Press.

Volkert, Klaus Thomas [1986]: Die Krise der Anschauung. Göttingen: Vandenhoeck \& Ruprecht.

Youschkevitch, A.P. [1976]: 'The concept of function up to the middle of the 19th century', Archive for History of Exact Sciences 16, 37-85.

Zermelo, Ernst [1908]: 'Untersuchungen über die Grundlagen der Mengenlehre - I', Mathematische Annalen 65 261-281. English translation 'Investigations in the foundations of set theory - I', in [van Heijenoort, 1967], pp. 199-215. 